\title{
Communicating About Translation: Task-based Speaking
}

\author{
Abdulmoneim Mahmoud \\ Sultan Qaboos University, Muscat, Sultanate of Oman
}

\begin{abstract}
This study views pedagogical translation as a means of developing language skills, especially oral communication. Contrary to the claim that translation focuses only on reading and writing, this study presents anecdotal evidence showing that a learner-centered approach to translation can help foreign language students improve their speaking skill through group work, problem-solving, and cooperative learning. To this end, the paper presents practical examples of lexical, structural, textual, and cultural issues that students discussed in their process-oriented Arabic-English-Arabic pedagogical translation courses at the university level. The students were divided into groups of three or four to work together at all stages of the translation process. They spent most of the class time comprehending the source text, translating it, and discussing each other's target versions. In the remaining class time, the whole class discussed a target text translated by any one of the groups. The students were instructed to use English in their group and whole-class deliberations. They were also instructed to use the appropriate language functions, structures, and expressions to achieve objectivity in their arguments. The study calls for further empirical research to verify the usefulness of the proposed learner-centered translation-based technique of teaching speaking.

Keywords: communication, group work, speaking, translation, whole-class discussion
\end{abstract}

\section{Introduction}

When translation is mentioned in connection with foreign language (FL) teaching, our minds flash back to the days of the Grammar-Translation method. Hence most, if not all, of the studies in this area are usually prefaced with a historical account of the role of translation in FL teaching and learning. They trace the use of the first language in general and translation in particular from the 1920s to the present day (see e.g., Machida, 2008; Mahmoud, 2006). Research shows that translation was criticized as a FL teaching technique simply because of its association with the Grammar-Translation method (Almog, 2009; Campisi, 2015). Thus, the use of translation in the FL classroom witnessed a lengthy period of fluctuation swinging from all to none until it settled somewhere in the middle. Some researchers (e.g., Mogahed, 2011; Vermes, 2010) stated that translation was a victim of the Grammar-Translation method, not the cause of its downfall. Many researchers talked about today's "revival”, "rehabilitation”, or "reconsideration" of translation in FL teaching, (e.g., Carreres, 2006; Cook, 2010; Leonardi, 2011; Marques-Aguado \& Solis-Becerra, 2013).

The researchers (listed above) who advocate the use of translation in FL teaching enumerate a list of linguistic and psychological benefits. They believe that it improves comprehension, consolidates structures, develops vocabulary and style, reduces the influence of the first language, encourages participation, lowers stress and anxiety, reduces avoidance, and it is in line with the students' cognitive strategy of linguistic transfer.

Abdulmoneim Mahmoud, professor of applied linguistics, M.A., Ph.D., Department of English, Sultan Qaboos University, Sultanate of Oman. 
These researchers also refer to the drawbacks of translation as listed by Newson (1998) and Malmkjaer (1998). Translation is believed to reduce the opportunities of using the FL in the classroom; it does not help the students develop communication skills. It is also believed to focus on the two skills of reading and writing. In addition, it is believed to lead to first language interference errors and prevent the students from thinking in the FL. However, the proponents of translation have refuted these views (see e.g., Dagiliene, 2012; Marques-Aguado, et al., 2013; Vermes, 2010).

The purpose of this study is to highlight the view that translation can be used to develop students' communication skills, especially speaking. It aims to provide practical evidence as to how translation helps the students to interact and communicate in the FL besides practicing the two skills of reading and writing. Thus, the study represents a counter-argument to the view that translation deprives the students of the speaking skill and militates against the development of communication skills in the FL. Al-Quyad (2014) and Ghaiyoomian and Zarei (2015) believe that translation develops the four language skills at all levels of proficiency. Almog (2009) goes further to add that it helps in developing the language skills not only in the FL but also in the first language. Many researchers agree that translation is a psycho-cognitive learning and communication strategy employed by FL students, and therefore it can be utilized in teaching the FL language (Fageeh \& Mekheimer, 2011; LIAO, 2006; Marques-Aguado et al., 2013; Mahmoud, 2013). According to Zohrevandi (1994), the fears of the critics of translation "are justified if translation is done in a traditional manner, but not if its use is modernized and streamlined to communicative strategies" (p. 186). Carreres (2006) adds "the task-based approach appears to lend itself particularly well to the teaching of translation” (p. 17).

An important step to break away from the traditional technique of translating decontextualized words and sentences is to view translation as a communicative activity involving interaction between people from different linguistic backgrounds (Al-Quyad, 2014; Campisi, 2015; Pekkanli, 2012). It "serves as a means of information delivery in various situations" (Zhao, 2015, p. 4). Therefore, the translation task has to be one of translating contextualized texts reflecting the real life process of conveying thoughts and ideas across two or more languages. This communicative nature of translation enriches discussion and communication among the students.

Instead of viewing translation as one of the techniques of FL teaching, the present study views FL learning as one of the outcomes of teaching translation. In other words, a translation course is seen as an opportunity for task-based communicative teaching and learning of the FL. The paper focuses on the teaching of translation as a task to practice oral communication through group discussion, interaction, and negotiation. Speaking is a vital language skill at the university level where the FL (English) is the medium of instruction. The students need to ask and answer questions in the lectures and they are also required to give oral presentations, attend workshops and conferences, and participate in various activities, such as exhibitions, societies, and contests. Thus, this paper sheds light on the use of translation as a task-based technique of teaching speaking in a real communicative situation. Most of the studies conducted in this regard so far are only suggestions and hypothetical accounts of how to use translation as one of the FL teaching techniques (e.g., Cook, 2010; Campisi, 2015; Dagiliene, 2012; Stibbard, 1998; Vaezi \& Mirzaei, 2007).

\section{Related Studies}

Some studies were conducted with regard to the use of translation in FL pedagogy. These studies could be divided into two main types: (1) studies that are mere suggestions without practical classroom application (e.g., 
Cook, 2010); (2) studies that focus on the translation of isolated words and sentences. Zohrevandi (1994), for example, used oral translation of words and idioms from the first language to the FL to write dialogues. Leonardi (2011) used translation of words from the first language to fill in gaps in a FL text. Calis and Dikilitas (2012) used translation of isolated sentences to teach certain FL forms and structures. None of the above-mentioned researchers utilized translation of full texts as a task-based technique of teaching oral communication in the FL.

In the light of the limitations observed in the previous studies and in response to the assumption that pedagogical translation ignores speaking, the present study is intended to fill in the gap by demonstrating how translation can be used as a means to practice speaking in a FL classroom. The discussion is informed by the present researcher's experience in teaching language and translation to Arab EFL university students over the past 25 years. Data for this study were collected from classroom organization and observation of process-oriented group translation of texts by male and female Arts and Education English majors in Sultan Qaboos University (SQU), Oman. These students study introductory courses in English-Arabic-English translation as part of their BA literature and BA ELT programs. Education students study only one translation course whose main objective is to develop their English proficiency. For education students who become translators, this course provides some basic techniques and ideas that can help them in their profession. Arts students study three practical courses and one theoretical course in translation. Again the main aim is to reinforce their competence in English and to lay the foundation for possible professional translation. Thus, these pedagogical translation courses are intended to help the students develop their competence in English in the first place and to provide them with some introductory knowledge of translation as a basis for possible future professional translation. Two important objectives that are reiterated in all of the BA English courses in these two SQU colleges are problem-solving and critical thinking - the higher order cognitive skills of analysis, synthesis, and evaluation. Researchers (e.g., Fisher, 2007; Shirkhani \& Fahim, 2011; Yang \& Gamble, 2013) agree that these skills improve the students' language skills. Therefore, they are viewed as important elements in language teaching. It goes without saying that translation is an activity that requires problem-solving and critical thinking at all of its stages of comprehension, rendering, and editing.

In these courses, the instructor (the present researcher) follows a learner-centered approach where the students are encouraged to shoulder the responsibility of their own learning. The essence of using process-oriented translation as a learner-centered communicative activity is group work and cooperative learning where the students talk to and learn from each other in a relaxed situation. Group work and cooperation in problem-solving are classroom activities that help the students "negotiate meaning and use language for real communication in a non-threatening atmosphere” (Hwang \& Huang, 2007, p, 28). Hence, in the above-mentioned translation courses, the instructor acts as an organizer and reference and delegates the task to the students (15-20 students) throughout the class session. The students translate short texts (80-100 words) from English to Arabic or vice versa depending on the course description. The texts are compiled by the instructor from various sources (books, magazines, newspapers, technical reports, etc.) in such a way as to represent different text types and fields of knowledge (technology, business, science, culture, social and psychological topics, notices, advertisements, etc.). The students are divided into groups of three or four according to the places they wish to sit and the classmates with whom they wish to work. They are given clear instructions to speak in English throughout the semester and they are constantly reminded to do so. In addition, 
the instructor systematically makes the rounds of all groups while they are working to make sure that they discuss and communicate in English.

Group work and cooperation in problem-solving and task performance start from the first stage where the students help each other with the meanings of the unfamiliar words and concepts. However, some students prefer to use electronic dictionaries installed in their mobile phones in order not to interrupt their colleagues. Having finished reading the source text, the students are asked to translate it first individually to ensure that all of them perform the task and to safeguard against being affected by and accepting others' translation without scrutiny. The members of each group then get together to discuss their translations and arrive at a final version of the target text. Collaboration and interaction are the essential classroom procedures aimed at developing critical thinking and problem-solving skills. The students in groups and as a whole class read each other's translations critically and justify their arguments. Every session, one group is chosen to write their version on a transparency to be projected for the whole-class discussion.

\section{Issues Discussed}

As Leonardi (2011) says, "translation is a complex activity which involves linguistic, cultural and cognitive factors" (p. 18). This fact gives impetus to communication and discussion in process-oriented group and whole-class work. Classroom observation of various batches of students for 25 years revealed that almost all of the group and whole-class discussion of translation centered around linguistic and cultural issues in both the source and the target texts. Most of the linguistic problems discussed were related to the use of the lexical items. At the translation stage, the students would judge whether a word or phrase used was semantically correct or stylistically appropriate. The following are a few examples from the two languages involved (Arabic and English).

\section{Lexical Items}

One of the frequently discussed problems was the selection of words from regional varieties, such as underground-subway, billion-milliard-trillion, or different styles and registers, such as children-kids, adolescents-teens, obese-fat, “mawjat”-“amwaj” (Arabic frequency waves vs. sea waves respectively).

Some students would use unfamiliar classical Arabic words, thus triggering an argument as to whether the audience would understand such words. For example, using "kunh" instead of the more commonly used word "fahm" for "to understand" in the sentence "The students should understand that English is important not only for....". On the other hand, they would judge some Arabic words, such as "kabl” (cable) as inappropriate, because they were non-standard.

Discussion of options also included the differences between Arabic and English in cases where one language uses one word that has two or more equivalents in the other language, for example, "yalbas" (put on—wear), “mudeer” (director—manager), “arabi” (Arab, Arabic, Arabian), “yunazzim” (organize—regulate).

Students' discussions were also motivated by selection problems encountered in Arabic. For instance, they would talk about the differences between groups of words, such as (1) wasal (arrived), wassal (connected), ittasal (contacted), tawasal (communicated); (2) yusallif (to lend) and yastalif (to borrow), (3) yujannib (to keep away from) and yatajannab (to avoid). The translation of the English word "carefully" in the sentences "The goods are carefully packed" and "The packages are carefully marked” generated a lot of discussions since two different words were needed in Arabic. 
Which technique of translation to use also constituted a point of discussion, especially when rendering English technical terms, such as microwave, computer, gene, and fax. They would discuss the choice between translation, adaptation, and transliteration and justify their choice. For instance, some students defended the translation of "computer" as "hasoob" as a proper translation while others opted for the adapted word "kombuter" as a commonly used equivalent.

Collocations in English and Arabic invited a lot of discussion, especially in cases where the students translated word for word from Arabic to English and committed errors such as *inclusive change (comprehensive), *protective medicine (preventive), and *generous life (decent). Collocations also caused problems when translating from English to Arabic. For example, in a text about cosmetic surgery, the writer used phrases, such as "reshaping the skin, replacing the hair, removing the fat". The students engaged in a lengthy discussion to come up with the appropriate Arabic words (tarmeem, ziraah, shaft) that would collocate with skin, hair, and fat respectively.

Needless to say, the selection of lexical items is also governed by cultural, religious, and logical considerations. Such factors usually constitute points of deliberation among the students. For example, when translating "royal approval" into Arabic, some students were not satisfied with the word "muwafaga" as an appropriate equivalent of "approval"; they explored other options to express a more elevated notion. In an English text about genetic engineering, the students deliberated on the religious connotations of the word "create" in "creating new life in the laboratory". When translating the phrase "lose weight", some students thought that the use of the word "lose" was logically inappropriate since people would usually be happy to "lose" something they do not want. They suggested using the Arabic phrase "yatakhallas min" (get rid of). In the same vein, the students criticized a writer of an Arabic text about photography because of the use of the word "mawhiba". In a group translation, it was correctly rendered as "talent". In the whole-class discussion, however, some students from the other groups thought the writer should have used "hiwaya" (hobby). These last two examples show that the students' discussions also included judgements not only about the language but also the concepts used in the source text.

\section{Comprehension Problems}

Issues related to comprehension were also discussed in both the source and target texts. Most of the discussions were related to the meanings of the words and expressions. Due to the inadequate coverage of the electronic mobile dictionaries, the students had to work out the meanings of the unfamiliar words in the English source texts by themselves. In addition, the students had to resolve ambiguity. For instance, in the sentence, "New plants will be developed using nitrogen from the air", the contracted relative clause led some students to argue that the subject of "using" was the plants while others thought it was the scientists. Ambiguity problems were also encountered in the Arabic source texts because usually vocalization marks (short vowels) are not used in most modern written texts. For example, the Arabic words "turaddu" (returned) and "taridu" (imported) are both written as "trd" without vowels and no doubling of consonants. Hence, the students deliberated on two possible translations: "goods that are returned" versus "goods that are imported". At the comprehension stage, the students would discuss some linguistic features pertaining to the style of the source text, such as word choice and repetition. For example, in an Arabic text about smoking, the students in more than one group discussed why the writer said "seven days" and not "one week" and why s/he repeated the number in "I quit smoking a thousand times and returned to it a thousand times". 


\section{Grammar, Translation Techniques and Language Functions}

The students also deliberated on some grammar problems in areas, such as prepositions and the use of the perfect tense in English. These areas caused problems due to the differences between Arabic and English. The students would usually use the simple past tense where the present perfect was required in English. They also expected one-to-one correspondence in prepositions. However, discussion of such grammar points would always be prompted by the instructor. The students discussed lexical problems more than grammar most probably because they thought lexical items were more important than grammar in conveying meaning.

In an introductory lecture at the beginning of the semester, the students are usually taught some basic translation rules and techniques to follow when translating and editing individually, in group and as a whole class. They are also given a two-page handout summarizing these rules and techniques. Hence the students would engage in discussions related to the application of these rules and techniques. For example, they would discuss and justify addition, omission, or reordering of some words or parts and changing a sentence from the passive voice to the active voice or from direct to indirect speech or from nominal to verbal or vice versa, or changing a noun from singular to plural or vice versa. At the group translation stage, in case of disagreement between the group members, they were instructed to list the various options they would come up with. Such options, whether lexical, grammatical, cultural, or textual, would constitute points of deliberation at the whole-class discussion stage. At the whole-class discussion stage, the students were encouraged to ask questions to verify their target options or versions if different from those given by the group whose translation was being discussed. The instructor would initiate further discussion by indicating any other linguistic, cultural, conceptual, or textual issues that needed to be resolved. Depending on the time available and the type of text, the instructor would create more opportunities for communication by encouraging the students to comment on the views expressed in the source text, especially if the topic was argumentative (e.g. intermarriage).

In addition to cooperative learning, form-focused and meaning-focused communication, and critical thinking, the whole-class discussion of translation also helped the students learn and practice some basic principles of argumentation, such as suggestion, justification, agreement, disagreement, and refutation using various politeness formulae and expressions. The students were encouraged to be as objective as possible by focusing on the translations rather than the translators. To achieve that goal, the students had to practice the use of the passive voice and the present perfect tense when describing each other's translations (e.g., the word ... has been/has not been used). They also used modals, such as can, may, would, and could, when proposing alternative translation equivalents.

Judgements about the usefulness of the proposed technique of teaching speaking by communicating about translation are based on the ample opportunity the students got through group and whole-class discussions which used to take up most of the class time. The task-based oral communication would start from the source text comprehension stage and continue throughout the translating and editing stages. However, a problem that is inherent in group work lies in the difficulty of ensuring that all of the students in all groups use English in their discussions since the instructor can attend to only one group at a time. In the present study, some students were observed switching to their first language (Arabic) for the sake of clarity and ease of communication, something which they were instructed not to do unless it was absolutely necessary. However, the students used a few Arabic words and phrases spontaneously as fillers, comprehension checks, and clarification request and questions at the group discussion stage. Ease of communication also led to a few instances of "foreignization" 
where the students produced English words with Arabic affixes. For example, in an English source text, the instructor drew the students' attention to the use of collocations as the most salient linguistic feature. Hence, the "foreignized" word "collocationat" (at = Arabic feminine plural bound morpheme) was used by more than one student in group discussion. Fortunately, all such creations were cases of positive foreignization because the students knew the English root words as opposed to negative foreignization where the learners do not know the English root word, therefore the Arabic root is given a productive English affix. To reduce possible code-switching resulting from fear of making mistakes, the student were told not to worry about mistakes when talking to the group or to the whole class. They were also advised not to correct each other in order not to interrupt the flow of communication if comprehension was maintained.

\section{Conclusion}

Most of the studies discussing the role of translation in FL teaching start with a historical account, list the pros and cons of the technique, and end with the revival of translation in this era of communicative language teaching. These studies focus on teaching language skills using translation as one of techniques. In this study, however, the focus was on teaching translation as a skill in its own right with the development of language skills as one of its outcomes. Translation was viewed as a catalyst for improvement of not only reading and writing but also for practicing speaking in a genuine communicative situation through group interaction and cooperative learning to solve translation problems. Needless to say, translation also helps in language awareness and critical thinking. This study sought to show that pedagogical translation courses at the university level can be used to develop the students' oral communication skills through group and whole-class discussion. To this end, practical examples were presented based on 25 years of university teaching experience. Following a learner-centered approach, the students were encouraged to shoulder the responsibility of their own learning at all stages of the translation process. They would work in groups to figure out the meanings of the unfamiliar words, expressions, and concepts in the source text. The group would then translate the text and discuss each member's target version. The group translation was then projected for the whole-class discussion. The students were instructed to use English in their deliberations throughout the class session. In addition to the development of the language skill and problem-solving and critical thinking skills, group and whole-class discussions offered an opportunity to practice social and interpersonal skills and some language functions including argumentation techniques and politeness expressions. The findings of this study remain anecdotal based on extensive teaching experience and classroom observation. Further empirical research is needed to verify the usefulness of the proposed translation-based speaking technique.

\section{References}

Almog, R. (2009). Teaching translation skills program in an Israeli high school (M.A. thesis, Bar Ilan University).

Al-Quyad, A. (2014). The teaching of translation at the university level: Constraints and aspirations. Arab World English Journal, 5(2), 133-141.

Calis, E., \& Dikilitas, K. (2012). The use of translation in EFL classes as L2 learning practice. Procedia-Social and Behavioral Sciences, 46, 5079-5084.

Campisi, N. (2015). The use of translation in the language classroom. Center for language studies. Retrieved from http://blogs.brown.edu/language_studies/2015/20/the-use-of-translation-in-the-language-classroom

Carreres, A. (2006). Strange bedfellows: Translation and language teaching. Paper presented at The 6th Symposium on Translation, Terminology and Interpretation, Havana, Cuba. Retrieved from http://www.cttic.org/ACTI/2006/paper/Carreres.pdf 
Cook, G. (2010). Translation in language teaching. Oxford: Oxford University Press.

Dagiliene, I. (2012). Translation as a learning method in English language teaching. Studies About Language, 21, 124-129.

Fageeh, A., \& Mekheimer, M. (2011). EFL learners' vocabulary acquisition in translational writing. Journal of Language Teaching Research, 2(4), 918-928.

Fisher, A. (2007). Critical thinking: An introduction. Cambridge: Cambridge University Press.

Ghaiyoomian, H., \& Zarei, G. (2015). The effect of using translation on learning grammatical structures. IJRELT, 3(10), 32-39.

Hwang, Y., \& Huang, P. (2007). Learning together. English Teaching Professional, 53, 28-29.

Leonardi, V. (2011). Pedagogical translation as a naturally occurring cognitive and linguistic activity in foreign language learning. Annali Online di Lettere-Ferrara, 2, 17-28.

Liao, P. (2006). EFL learners' beliefs about and strategy use of translation in English learning. RELC, 37(2), 191-215.

Machida, S. (2008). A step forward to using translation to teach a foreign/second language. Electronic Journal of Foreign Language Teaching, 5, 140-155.

Mahmoud, A. (2006). Translation and foreign language reading comprehension: A neglected didactic procedure. English Teaching Forum, 44(4), 28-30.

Mahmoud, A. (2013). Learner involvement in language development. Academic Exchange Quarterly, 17, 35-46.

Malmkjaer, K. (1998). Introduction: Translation and language teaching. In K. Malmkjaer (Ed.), Translation and language teaching (pp. 1-11). Manchester: St. Jerome.

Marques-Aguado, T., \& Solis-Becerra, J. (2013). An overview of translation in language teaching methods. Revista de Linguistica y Lenguas Aplicadas, 8, 38-48.

Mogahed, M. (2011). To use or not to use translation in language teaching. Translation Journal, 15(4), 2-4.

Newson, D. (1998). Translation and foreign language learning. In K. Malmkgaer (Ed.), Translation and language teaching (pp. 63-68). Manchester: St. Jerome.

Pekkanli, I. (2012). Translation and the contemporary language teacher. Procedia-Social and Behavioral Sciences, 46, 955-959.

Shirkhani, S., \& Fahim, M. (2011). Enhancing critical thinking in foreign language learners. Procedia-Social and Behavioral Sciences, 29, 111-115.

Stibbard, R. (1998). The principled use of oral translation in FL teaching. In K. Malmkgaer (Ed.), Translation and language teaching (pp. 69-76). Manchester: St. Jerome.

Vaezi, S., \& Mirzaei, M. (2007). The effect of using translation from L1 to L2 as a teaching technique. Retrieved from http://www.htlmag.co.uk/Sep07/mart03.rtf

Vermes, A. (2010). Translation in foreign language teaching: A brief overview of pros and cons. Eger Journal of English Studies, 10, 83-93.

Yang, Y., \& Gamble, J. (2013). Effective practical critical thinking in EFL instruction. EFL Journal, 10(4), 1093-1100.

Zhao, Y. (2015). Using translation in ESL classrooms: An Asian perspective. International Journal of Innovative Interdisciplinary Research, 14, 83-51.

Zohrevandi, Z. (1994). Translation as a resource. In M. Heliel (Ed.), Language, discourse and translation. Amsterdam: John Benjamins. 